\title{
Growth-promoting effects of marine microalgae species using tropical forest soil extracts
}

\author{
Kasturi Arumugam ${ }^{1}$, Nor Suhaila Yaacob ${ }^{2 *}$, Hasdianty Abdullah², Mohd Fadzli Ahmad', Maegala Nallapan Maniyam², \\ Emi Fazlina Hashim ${ }^{4}$, Fridelina Sjahrir ${ }^{1}$, Wan Muhammad Ikram¹, Kazuhiro Komatsu ${ }^{5}$, Victor S. Kuwahara ${ }^{4}$ \\ ${ }^{1}$ Faculty of Engineering Life Sciences, Department of Science Biotechnology, Universiti Selangor, Selangor, Malaysia. \\ ${ }^{2}$ Institute of Bio-IT Selangor, Universiti Selangor, Selangor, Malaysia. \\ ${ }^{3}$ Centre for Foundation and General Studies, Universiti Selangor, Selangor, Malaysia. \\ ${ }^{4}$ Faculty of Education Graduate School of Engineering, Soka University, Hachioji-Shi, Japan. \\ ${ }^{5}$ Regional Environmental Conservation Division, National Institute for Environmental Studies, Tsukuba, Japan.
}

\section{ARTICLE INFO \\ Article history: \\ Received on: June 30, 2021 \\ Accepted on: September 04, 2021 \\ Available online: February 15, 2022}

Key words:

Growth, microalgae, soil extracts, sustainability, treatment

\begin{abstract}
Microalgae are a source of high-value substances beneficial for industrial applications. To augment the mass production of microalgae in an artificial culture medium, growth-promoting nutrients are essential. The effect of soil extracts (SEs) on four microalgae species was investigated in this study. Artificial Conway media were supplemented with SE collected from the Ayer Hitam Forest Reserve and Raja Musa Forest Reserve (RM), tested using a microplate-incubation technique. The samples were cultured for nine days at $25^{\circ} \mathrm{C}$ and $30^{\circ} \mathrm{C}$, with a light intensity of $33.75 \mathrm{~mol}$ photons $\mathrm{m}^{-2}$ seconds ${ }^{-1}$ and a 12-hour light/dark cycle. Incubation at $25^{\circ} \mathrm{C}$ showed a higher specific growth rate (SGR) for Nannochloropsis oculata $\left(0.32-0.39 \mathrm{~d}^{-1}\right)$, while, at $30^{\circ} \mathrm{C}$, a higher SGR was observed for Dunaliella tertiolecta in all soil treatments $\left(0.31-0.34 \mathrm{~d}^{-1}\right)$. In terms of SEs, media + RM SE showed a higher SGR from 0.25 to $0.39 \mathrm{~d}^{-1}$ for four microalgae. Chlorella sorokiniana and $N$. oculata grew well at $25^{\circ} \mathrm{C}$ in all soil treatments, while D. tertiolecta and Dunaliella primolecta grew well at $30^{\circ} \mathrm{C}$. This study shows that the RM medium was the optimum soil treatment for all microalgae tested due to the higher concentration of organic matter.
\end{abstract}

\section{INTRODUCTION}

Soils are dynamic and diverse natural ecosystems composed of rich organic matter derived from water, minerals, and living organism residues undergoing decomposition processes [1]. Some soils provide an eutrophic environment containing all the fundamental nutrients ideal for microalgae growth relative to artificial media [2]. Artificial seawater media for microalgae growth were developed by eliminating soil extracts (SEs) and substituting them with vitamins, trace metals, chelators, and other organic additives, as initially revealed by [3]. Growth-promoting SE activity was mainly ascribed to the humic component's chelating action, leading to reduced toxicity or increased trace metal accessibility [3]. As a result of its soil organic matter, SE could

\footnotetext{
*Corresponding Author

Nor Suhaila Yaacob, Institute of Bio-IT Selangor, Universiti Selangor, Selangor, Malaysia.E-mail: shuhaila@unisel.edu.my
}

play a key role in increasing microalgae biomass. However, due to the high cost and low yield of microalgal products, commercialscale applications of microalgal biomass are still limited [4]. However, few studies have tested the impact of growth-promoting effects from natural systems on aquatic microalgae. Moreover, no studies have been conducted on mass-culture systems designed to produce commercial-scale applications of microalgae biomass using natural growth-enhancing nutrients.

SE microelements are beneficial for algae cultivation [5]. Soil organic matter consists of various components such as carbon (C), hydrogen $(\mathrm{H})$, oxygen $(\mathrm{O})$, magnesium $(\mathrm{Mg})$, and small amounts of sulfur $(\mathrm{S})$, phosphorus $(\mathrm{P})$, calcium $(\mathrm{Ca})$, nitrogen $(\mathrm{N})$, and potassium (K) [6]. The different concentrations of SE influence microalgal growth and their protein content [7]. The higher concentration of SE increases the cell number without affecting algal morphology and their development in an extended period. The nitrogen and manganese content in the culture 
medium contribute by the SE promoted microalgal growth [5]. Furthermore, the carbon content in the soil also supports the algal growth along with other essential elements such as nitrogen and phosphorus [8]. According to Ramaraj et al. [9], most of the studies use the chemical medium to enhance algal growth.

Fertilizer-based culture media can increase microalgal development at a lower cost than an artificial culture medium with the same nutrient composition [10]. Refined and expensive chemicals were predominantly employed for microalgae bulk cultivation, which is not cost-effective for mass culturing [11]. Okauchi [12] also noted that the mass production of Chlorella in vitro using pure chemical media is costly. As a result, the search for less expensive sources of nutrients is always desirable. In addition to being cost-effective, adding a natural growth stimulant to the medium is another way to obtain high algae output.

In this study, soil samples from two tropical forest reserves, the Ayer Hitam Forest Reserve (AH, mineral soil) and Raja Musa Forest Reserve (RM, peat soil), were studied to identify if they have any natural growth-promoting properties in microalgae. Mineral soil is produced by wind or water that causes rock weathering and/or mineral material deposition. Meanwhile, peat soil is the accumulation of waterlogged plants, trunks, and root debris over 1,000 of years formed due to insufficient oxygen [13-15]. These two soil types have adequate carbon, nitrogen, and phosphorus content, which is crucial for microalgae. Cruz et al. [16] stated that the lack of any one of the organic matters could affect algal growth. The goal of this project is to assess the growth effects of tropical rainforest minerals and peat SEs on marine microalgae. More specifically, the goal is to discover new natural growth-enhancing material for microalgae mass culture.

\section{MATERIALS AND METHODS}

\subsection{SEs}

Two tropical rainforests were selected based on their pristine natural condition, which is undisturbed by human activity and remote from the marine environment. The $\mathrm{AH}$ soil was collected at $3^{\circ} 00^{\prime \prime} 27.7^{\prime \prime} \mathrm{N} 101^{\circ} 38^{\prime} 46.9^{\prime \prime} \mathrm{E}$, while the RM soil was collected at $3^{\circ} 26^{\prime} 45.2^{\prime \prime} \mathrm{N} 101^{\circ} 19^{\prime} 20.9^{\prime \prime} \mathrm{E}$. A random sampling technique was conducted according to the United States Department of Agriculture method. Soil surface or O horizon was removed, and samples were collected from the A horizon, with a maximum depth of 5 to $15 \mathrm{~cm}$. The randomly selected soil samples were mixed into one composite soil sample to form a $3 \mathrm{~kg}$ mixture for each site. Roots, woods, and stones were removed by hand, and the samples were oven-dried for 1 week at $60^{\circ} \mathrm{C}$. The dried soils were then ground using a $700 \mathrm{~g}$ Swing Type Electric Herbal Powder Grinder (Weifang City, Shandong, China), sieved using a $1 \mathrm{~mm}$ sieve, and homogenized. The samples were collected from three points (triangle) at a $1 \mathrm{~m}$ distance.

The soil samples were treated with aqueous extraction. Water was used as the solvent to prepare the SEs [17] because it is a chemical substance that dissolves a wide range of materials better than any other liquid. Around $20 \mathrm{~g}$ of each soil sample was mixed with Milli-Q water (ultrapure water) at a 1:10 ratio and autoclaved at $105^{\circ} \mathrm{C}$ for 1 hour, followed by centrifugation at $700 \times \mathrm{g}$ for
15 minutes (Allegra-30R Centrifuge, Beckman, Indiana, United States). A $0.7 \mathrm{~m}$ glass fibre filter (GF/F, Whatman) was used to filter the supernatant (about $150 \mathrm{ml}$ ) of SE. Each soil's filtered samples were stored at $4^{\circ} \mathrm{C}$ for further use. Chemical analysis of AH and RM SE filtrates was performed. The MD600/MaxiDirect photometer system was used to measure total dissolved nitrogen (TDN) and total dissolved phosphorus (TDP) (Lovibond Tintometer, Amesbury, United Kingdom). The nitrogen and phosphorus levels were determined in mg 1-1 using TDN and TDP of AH and RM SE filtrates, according to the instruction manual. The dissolved organic carbon (DOC) of each SE filtrate was analyzed using Total Organic Carbon Analyser (TOC)-L CSH (Shimadzu, Kyoto, Japan).

\subsection{Microalgae}

In this investigation, the microalgal species employed were Chlorella sorokiniana [National Institute for Environmental Studies (NIES)-2168], Nannochloropsis oculata (NIES-2145), Dunaliella tertiolecta (NIES-2258), and Dunaliella primolecta (NIES-2256). The primary mineral solution, trace metal solution, vitamin solution, silicate solution, and nitrate solution were all used to make Conway media [18]. In an autoclaved conical flask, $1,000 \mu \mathrm{l}$ of stock microalgae culture was inoculated into $50 \mathrm{ml}$ of sterile Conway medium. On a 12-hour light: 12-hour dark cycle, the cultures were grown at $25^{\circ} \mathrm{C} \pm 0.5^{\circ} \mathrm{C}$ with a light intensity of $33.75 \mu \mathrm{mol}$ photons $\mathrm{m}^{-2}$ seconds ${ }^{-1}$. The strains were utilized to test on SEs after 2 weeks of incubation to acclimate to the experimental conditions before the experiment.

High-throughput screening methods have been developed using microplates $[19,20]$. The microplate-incubation technique was conducted on the microalgae species in two types of SEs using a 96-well microplate, where the microplate was divided into several zones. To prevent evaporation, the microplate's border wells were filled with Milli-Q water up to $200 \mu$ l. The third column (blank) had $195 \mu \mathrm{l}$ of media $+5 \mu \mathrm{l}$ of SE, whereas the fourth column had $175 \mu \mathrm{l}$ of media $+5 \mu \mathrm{l}$ of SE $+20 \mu \mathrm{l}$ of microalgae (C. sorokiniana, experiment), to capture the exponential phase of microalgae, as illustrated in Figure 1. The 5th through 10th columns of the microplate were treated in the same way, with $N$. oculata (Column 6), D. tertiolecta (Column 8), and D. primolecta (Column 10). On the four distinct microalgae in another microplate, a medium without SE was employed as a control.

The total volume of each well in the microplate ( 8 rows and 12 columns) was $200 \mu 1$. The microplates were sealed with parafilm to prevent evaporation, preserve the microplate's air humidity, and avoid contamination. Under the settings, all microplates were incubated for nine days described above at different temperatures. According to Lürling et al. [22], Cyanobacteria and Chlorophyte species showed positive growth between $20^{\circ} \mathrm{C}$ and $35^{\circ} \mathrm{C}$, reported as the optimum temperature. Hence, the temperatures of $25^{\circ} \mathrm{C}$ and $30^{\circ} \mathrm{C}$ were used for the incubation. The optical density (OD) at $680 \mathrm{~nm}$ was measured every 24 hours using the Infinite M200 PRO microplate reader (Tecan, Austria) to determine microalgal growth. The OD at $680 \mathrm{~nm}$ is described as the absorption of visible radiation (the chlorophyll absorption peak is approximately 680 $\mathrm{nm}$ ), representing microalgal development [23]. Before the OD 


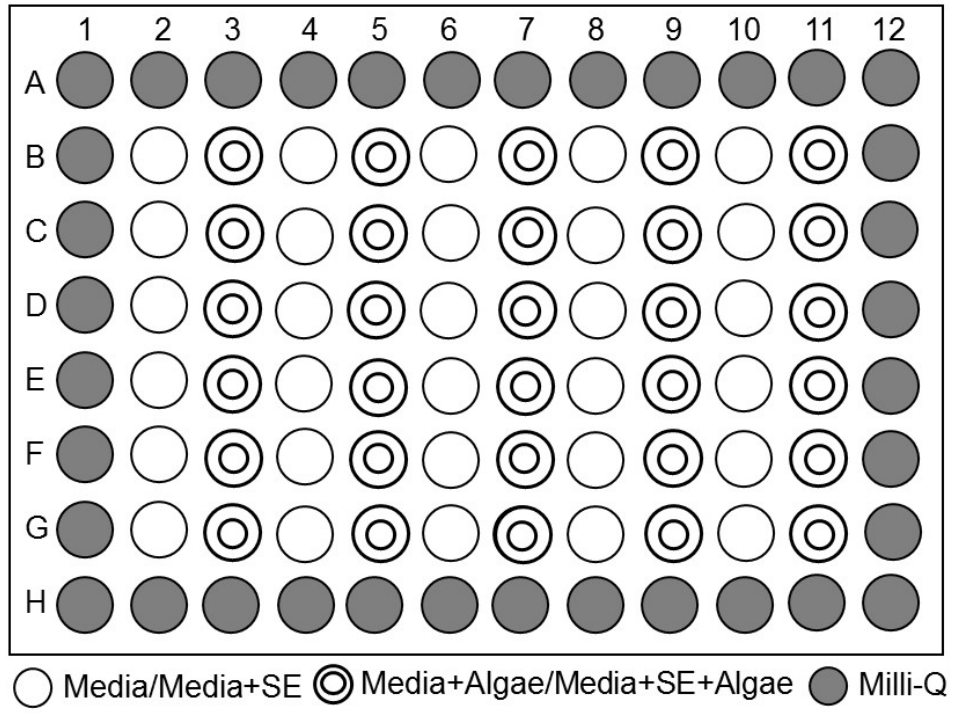

Figure 1: Microplate's border wells were filled with Milli-Q water up to $200 \mu$ l. The third column (blank) had $195 \mu$ l of media $+5 \mu$ of SE, whereas the fourth column had $175 \mu \mathrm{l}$ of media $+5 \mu \mathrm{l}$ of $\mathrm{SE}+20 \mu \mathrm{l}$ of microalgae.

measurement, an eight-channel Eppendorf pipettor was used to mix each of the wells containing controls and samples.

\subsection{Data analysis}

Each control and sample had six-well replicates in a column. Therefore, the sensitive mean value (SMV) of six-well OD replicates were calculated as follows:

$$
\mathrm{SMV}=\{\operatorname{Sum}(6)-\text { Minutes (1) }-\operatorname{Max}(1)\} / 4
$$

Microalgae specific growth rate (SGR) $(\mu)$ and division rate $(k)$ were estimated as follows:

$$
\begin{aligned}
& \mu=\frac{\ln \left(N_{2} / N_{1}\right)}{t_{2}-t_{1}}, \\
& k=\frac{\mu}{\ln 2},
\end{aligned}
$$

where $N_{2}$ and $N_{1}$ are the OD at times $t_{2}$ and $t_{1}$.

Student's $t$-test and one-way analysis of variance (ANOVA) corresponding to SMV of microalgae growth were used to analyze the DOC, TDN, and TDP content, as well as microalgae growth and maximum OD.

\section{RESULTS AND DISCUSSION}

\subsection{Chemical composition of SEs}

SEs from the tropical forest in Malaysia were used as an addition to the Conway media to grow four marine microalgae. Humic substances in the AH and RM SE are shown in Table 1. The DOC, TDN, and TDP in the RM SE are higher than those of AH SE. The ratio of $\mathrm{C}: \mathrm{N}$ in $\mathrm{RM} \mathrm{SE}$ is relatively higher than in AH SE.
In contrast, the ratios of $\mathrm{C}: \mathrm{P}$ and $\mathrm{N}: \mathrm{P}$ in $\mathrm{AH} \mathrm{SE}$ are higher than those in RM SE. However, no significant differences $(p>0.05)$ are detected between organic matter ratios in both SEs.

The three primary biogenic components are $\mathrm{C}, \mathrm{N}$, and $\mathrm{P}$, renowned for their roles as mass and energy flow carriers in ecosystems [24]. According to Yu et al. [25], soil nutrients could be modified by plants, yielding a forest-type Redfield ratio that can be used to test the stability of the ecosystem. Furthermore, the C, N, and P distribution patterns dictate the stoichiometric features of $\mathrm{C}: \mathrm{N}: \mathrm{P}$, and their influencing variables indicate the connections between ecological biogeochemistry and peatland structures, functions, and processes [26]. Thus, the Redfield C:N:P ratio was employed to determine the content of soil organic matter in a tropical forest $\mathrm{SE}$ in this study.

The Redfield ratio refers to a well-constrained C:N:P proportion in a plankton population of an aquatic ecosystem [27]. As mentioned by [26], the $\mathrm{C}: \mathrm{N}$ ratios would remain relatively constant in a narrow range, whereas $\mathrm{C}: \mathrm{P}$ and $\mathrm{N}: \mathrm{P}$ ratios differed significantly, depending on the ecosystems. However, the C:N, C:P, and N:P in this study showed no significant differences between $\mathrm{AH}$ and RM SE. The C:N:P ratios for AH SE and RM SE were 239:18:1 and 147:6:1. As stated by [28], on average, the C:N:P ratio for the terrestrial ecosystem in worldwide soil was 186:13:1. This proved that $\mathrm{AH}$ and RM SEs have higher $\mathrm{C}, \mathrm{N}$, and $\mathrm{P}$ composition, which could enhance microalgal growth.

\subsection{The effects of modified SEs and incubation temperatures on the microalgae species}

Temperature is a typical environmental variable that has a considerable impact on algae growth efficiency [29]. Due to nutritional conditions and light intensity, different microalgae require different optimal temperatures to grow. Previous research has found that temperature has a significant impact on algae 
Table 1: Soil organic matter in AH and RM SEs.

\begin{tabular}{lcccccc} 
SE & $\begin{array}{c}\text { DOC } \\
\left(\mathbf{m g ~ l}^{-1}\right)\end{array}$ & $\begin{array}{c}\text { TDN } \\
\left(\mathbf{m g ~ l}^{-1}\right)\end{array}$ & $\begin{array}{c}\text { TDP } \\
\left(\mathbf{m g ~ l ^ { - 1 }}\right)\end{array}$ & C:N & C:P & N:P \\
AH SE & $90.65 \pm 0.00^{\mathrm{a}}$ & $7.00 \pm 0.01^{\mathrm{c}}$ & $0.38 \pm 0.00^{\mathrm{b}}$ & 12.95 & 238.55 & 18.20 \\
RM SE & $1,032.10 \pm 0.04^{\mathrm{a}}$ & $45.20 \pm 0.03^{\mathrm{b}}$ & $6.90 \pm 0.01^{\mathrm{c}}$ & 22.83 & 149.57 & 6.55 \\
\hline
\end{tabular}

${ }^{a}$ cMean values with different superscripts are significantly different $(\mathrm{p}<0.05)$ using ANOVA and Turkey's post hoc.

Table 2: Effect of different incubation temperatures and modified SEs on the maximum OD and division rate of $C$. sorokiniana, $N$. oculata, D. tertiolecta, and D. primolecta.

\begin{tabular}{|c|c|c|c|c|}
\hline $\begin{array}{l}\text { Incubation } \\
\text { temperature }\end{array}$ & Species & Modified SE & Maximum OD & Division rate $k\left(\mathrm{~d}^{-1}\right)$ \\
\hline \multirow[t]{12}{*}{$25^{\circ} \mathrm{C}$} & \multirow[t]{3}{*}{ C. sorokiniana } & Control & $1.20 \pm 0.02^{\mathrm{a}}$ & $0.46 \pm 0.02^{\mathrm{a}}$ \\
\hline & & Media + AH SE & $1.08 \pm 0.03^{\mathrm{b}}$ & $0.41 \pm 0.02^{\mathrm{b}}$ \\
\hline & & Media + RM SE & $1.47 \pm 0.03^{\mathrm{a}}$ & $0.50 \pm 0.03^{\mathrm{a}}$ \\
\hline & \multirow[t]{3}{*}{ N. oculata } & Control & $1.03 \pm 0.03^{b}$ & $0.50 \pm 0.03^{\mathrm{a}}$ \\
\hline & & Media + AH SE & $1.07 \pm 0.03^{\mathrm{b}}$ & $0.47 \pm 0.02^{\mathrm{a}}$ \\
\hline & & Media + RM SE & $2.01 \pm 0.03^{\mathrm{a}}$ & $0.56 \pm 0.01^{\mathrm{a}}$ \\
\hline & \multirow[t]{3}{*}{ D. tertiolecta } & Control & $0.29 \pm 0.02^{\mathrm{b}}$ & $0.43 \pm 0.02^{\mathrm{a}}$ \\
\hline & & Media + AH SE & $0.28 \pm 0.02^{\mathrm{b}}$ & $0.43 \pm 0.02^{\mathrm{a}}$ \\
\hline & & Media + RM SE & $0.45 \pm 0.02^{\mathrm{a}}$ & $0.50 \pm 0.03^{\mathrm{a}}$ \\
\hline & \multirow[t]{3}{*}{ D. primolecta } & Control & $0.27 \pm 0.01^{\mathrm{a}}$ & $0.40 \pm 0.02^{\mathrm{a}}$ \\
\hline & & Media + AH SE & $0.25 \pm 0.02^{\mathrm{a}}$ & $0.33 \pm 0.01^{b}$ \\
\hline & & Media + RM SE & $0.26 \pm 0.02^{\mathrm{a}}$ & $0.37 \pm 0.02^{\mathrm{b}}$ \\
\hline \multirow[t]{12}{*}{$30^{\circ} \mathrm{C}$} & \multirow[t]{3}{*}{ C. sorokiniana } & Control & $0.83 \pm 0.03^{\mathrm{a}}$ & $0.44 \pm 0.03^{\mathrm{a}}$ \\
\hline & & Media + AH SE & $0.78 \pm 0.03^{\mathrm{a}}$ & $0.38 \pm 0.03^{\mathrm{a}}$ \\
\hline & & Media + RM SE & $0.81 \pm 0.03^{\mathrm{a}}$ & $0.40 \pm 0.03^{\mathrm{a}}$ \\
\hline & \multirow[t]{3}{*}{ N. oculata } & Control & $1.02 \pm 0.03^{\mathrm{a}}$ & $0.45 \pm 0.01^{\mathrm{a}}$ \\
\hline & & Media + AH SE & $1.14 \pm 0.03^{\mathrm{a}}$ & $0.47 \pm 0.01^{\mathrm{a}}$ \\
\hline & & Media + RM SE & $1.44 \pm 0.03^{b}$ & $0.49 \pm 0.01^{\mathrm{a}}$ \\
\hline & \multirow[t]{4}{*}{ D. tertiolecta } & Control & $0.50 \pm 0.02^{\mathrm{b}}$ & $0.49 \pm 0.02^{\mathrm{a}}$ \\
\hline & & Media + AH SE & $0.53 \pm 0.02^{\mathrm{b}}$ & $0.45 \pm 0.01^{\mathrm{a}}$ \\
\hline & & Media + RM SE & $0.68 \pm 0.02^{\mathrm{a}}$ & $0.49 \pm 0.01^{\mathrm{a}}$ \\
\hline & & Control & $0.50 \pm 0.02^{\mathrm{b}}$ & $0.44 \pm 0.02^{\mathrm{a}}$ \\
\hline & \multirow[t]{2}{*}{ D. primolecta } & Media + AH SE & $0.59 \pm 0.03^{\mathrm{a}}$ & $0.43 \pm 0.02^{\mathrm{a}}$ \\
\hline & & Media + RM SE & $0.64 \pm 0.02^{\mathrm{a}}$ & $\pm 0.02^{\mathrm{a}}$ \\
\hline
\end{tabular}

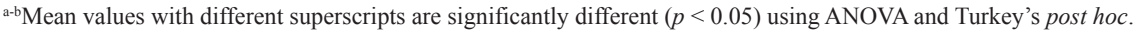

species' nutrient intake, carbon dioxide $\left(\mathrm{CO}_{2}\right)$ uptake, cellular chemical composition, and growth rates [30-33]. As a result, the growth of microalgae may be affected by a wide range of temperatures.

All four microalgal species exhibit a positive growth pattern in all three media, including control, media $+\mathrm{AH} \mathrm{SE}$, and media $+\mathrm{RM} \mathrm{SE}$ at the incubation temperatures of $25^{\circ} \mathrm{C}$ and $30^{\circ} \mathrm{C}$. The exponential growth of $C$. sorokiniana is observed from days 4 to 6 at the incubation temperature of $25^{\circ} \mathrm{C}$, followed by a stationary phase until the end of cultivation (Fig. 2a). The maximum OD of $C$. sorokiniana incubated at $25^{\circ} \mathrm{C}$ is the highest in media + RM SE (Table 2). In comparison, at $30^{\circ} \mathrm{C}$, the control and media $+\mathrm{RM}$ SE showed a higher value of maximum OD than media $+\mathrm{AH}$ SE, as shown in Figure $2 \mathrm{~b}$. However, the growth of $C$. sorokiniana in the control, media $+\mathrm{AH}$
$\mathrm{SE}$, and media + RM SE did not show any significant differences ( $p>0.05$ ) according to Student's $t$-test. The overall growth of $N$. oculata at incubation temperatures of $25^{\circ} \mathrm{C}$ and $30^{\circ} \mathrm{C}$ is enhanced in modified RM and AH SE based on the OD, as shown in Figure 3a and $b$. The growth pattern at both incubation temperatures indicated no significant differences $(p>0.05)$ between the control and modified SEs. The maximum OD of $N$. oculata at $25^{\circ} \mathrm{C}$ and $30^{\circ} \mathrm{C}$ is higher in the media + RM SE than in other conditions (Table 2).

Figure $4 \mathrm{a}$ and $\mathrm{b}$ illustrates that at both temperatures the OD of $D$. tertiolecta increases in media $+\mathrm{RM} \mathrm{SE}$, but Student's $t$-test showed no significant differences $(p>0.05)$ between the control, media + AH SE, and media + RM SE. The maximum OD of $D$. tertiolecta at $25^{\circ} \mathrm{C}$ and $30^{\circ} \mathrm{C}$ showed the highest value in media + RM SE (Table 2). Moreover, Figure 5a and b depicts that the 

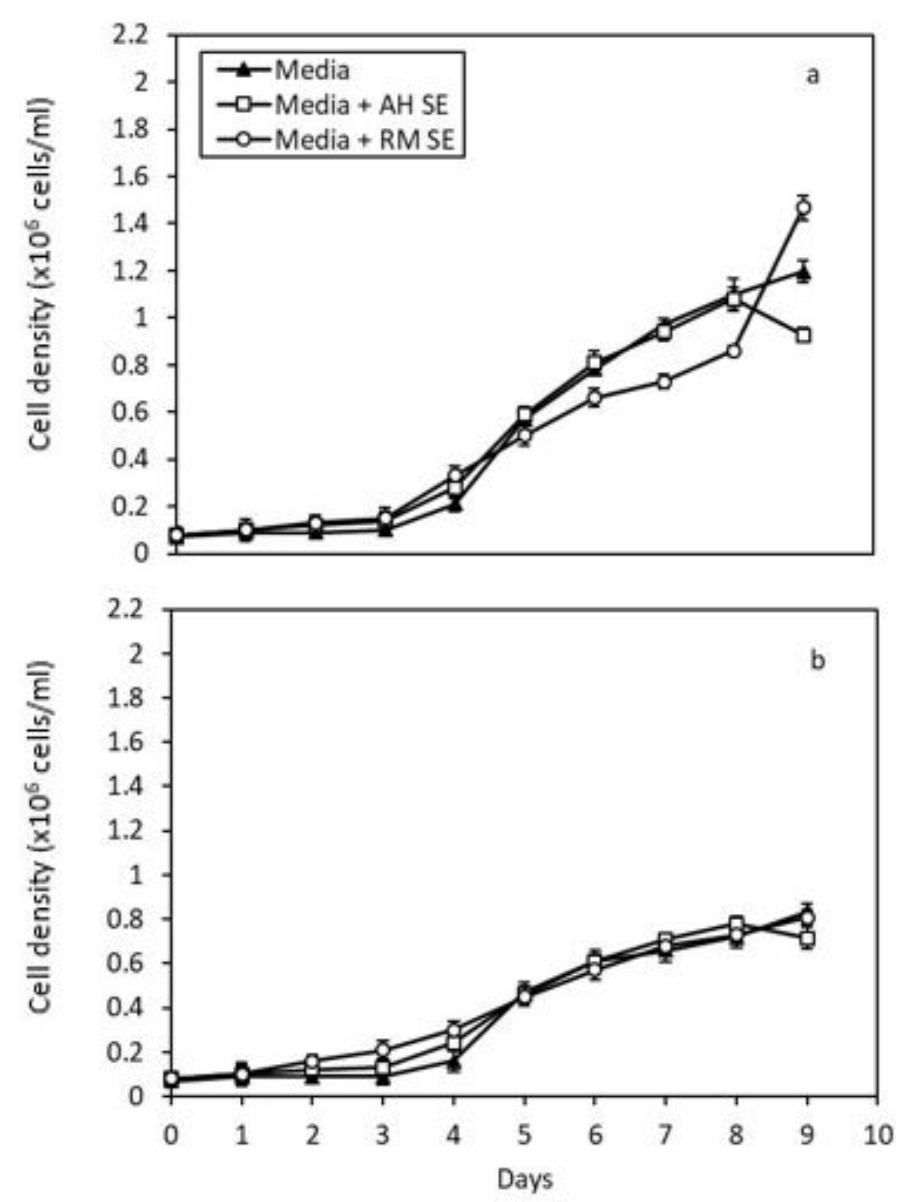

Figure 2: $\mathrm{OD}$ at $680 \mathrm{~nm}$ of the $C$. sorokiniana in media, media $+\mathrm{AH} \mathrm{SE}$, and media $+\mathrm{RM} \mathrm{SE}$ at $25^{\circ} \mathrm{C}$ (a) and $30^{\circ} \mathrm{C}(\mathrm{b})$. Error bars represent standard deviation $(n=6)$.

OD of $D$. primolecta increases in the control instead of media + $\mathrm{AH}$ SE and $\mathrm{RM} \mathrm{SE}$ at $25^{\circ} \mathrm{C}$ and $30^{\circ} \mathrm{C}$. Likewise, increased $\mathrm{OD}$ is observed in the media $+\mathrm{RM} \mathrm{SE}$, but no significant differences $(p$ $>0.05)$ are observed between the control and modified SE. The maximum OD of D. primolecta at $25^{\circ} \mathrm{C}$ is higher in control, and, at $30^{\circ} \mathrm{C}$, a higher value is observed in media + RM SE (Table 2).

Thus, no significant differences $(p>0.05)$ are observed between the OD of four microalgae species on modified SE at both incubation temperatures. In terms of maximum OD, C. sorokiniana, $N$. oculata, and D. tertiolecta have higher maximum OD in media + $\mathrm{RM}$ SE than the control and media $+\mathrm{AH} \mathrm{SE}$ at $25^{\circ} \mathrm{C}$. However, at $30^{\circ} \mathrm{C}$, a higher maximum OD is observed in media + RM SE for N. oculata, D. tertiolecta, and D. primolecta.

SGR of four microalgae species at $25^{\circ} \mathrm{C}$ and $30^{\circ} \mathrm{C}$ is higher in the modified SE, especially in media + RM SE, than in control. Media + RM SE showed significant differences compared to control at $25^{\circ} \mathrm{C}(p<0.05$, Figure $6 \mathrm{a})$. The SGR at $30^{\circ} \mathrm{C}$ showed lower values than those at $25^{\circ} \mathrm{C}$ (Figure $6 \mathrm{~b}$ ). Meanwhile, N. oculata showed the highest SGR and division rate at $25^{\circ} \mathrm{C}$ in the media $+\mathrm{RM}$ $\mathrm{SE}$, with 0.39 and $0.56 \mathrm{~d}^{-1}$, respectively (Table 2 ). In contrast, $D$. tertiolecta exhibited the highest SGR and division rate of 0.34 and $0.49 \mathrm{~d}^{-1}$ at $30^{\circ} \mathrm{C}$ in the control and media $+\mathrm{RM} \mathrm{SE}$. At $25^{\circ} \mathrm{C}$, the
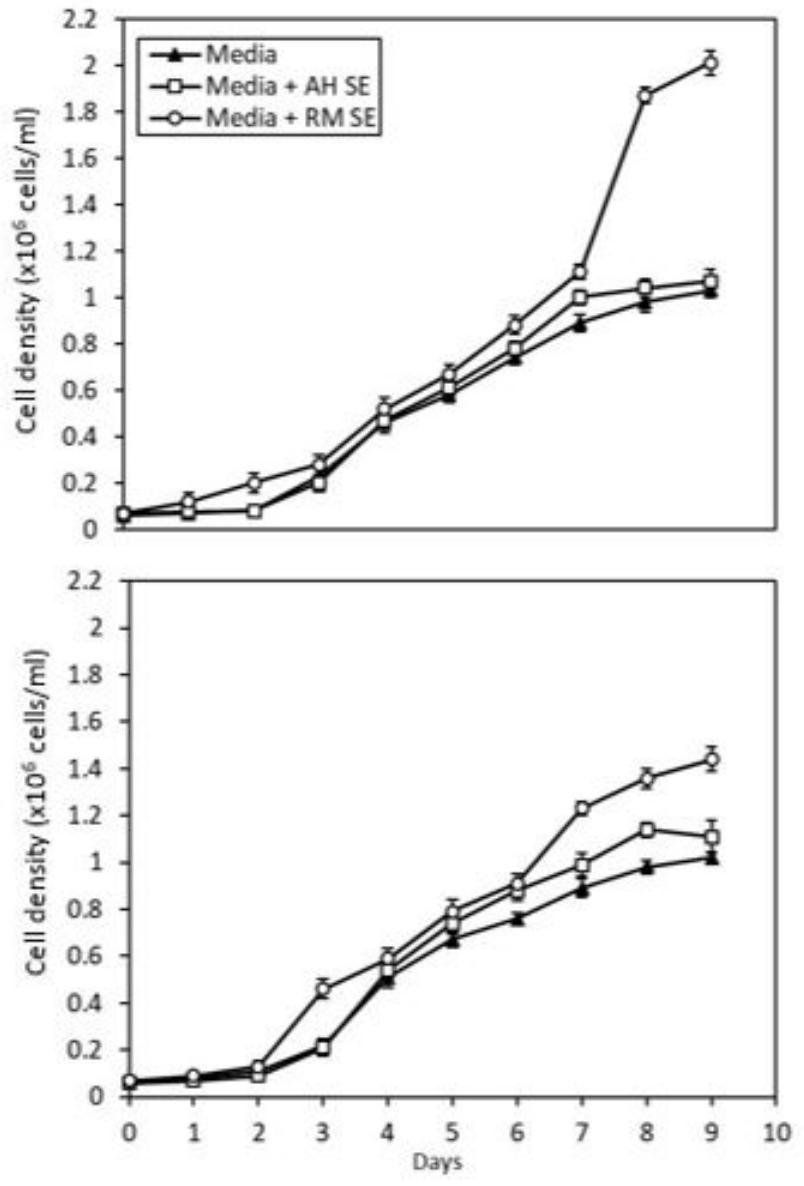

Figure 3: OD at $680 \mathrm{~nm}$ of the $N$. oculata in media, media $+\mathrm{AH}$ SE, and media $+\mathrm{RM} \mathrm{SE}$ at $25^{\circ} \mathrm{C}$ (a) and $30^{\circ} \mathrm{C}$ (b). Error bars represent standard deviation $(n=$ 6). Mean values are significantly different $(p<0.05)$ using ANOVA.

SGR of $N$. oculata is higher in all three types of media, while, at $30^{\circ} \mathrm{C}$, D. tertiolecta shows a higher SGR than the other microalgae species in the three media. The incubation temperature of $25^{\circ} \mathrm{C}$ is the optimum temperature for C. sorokiniana and $N$. oculata, while, for D. tertiolecta and D. primolecta, $30^{\circ} \mathrm{C}$ is optimum for their growth.

This study compared the growth of marine microalgae at different incubation temperatures on modified media. The SGR of C. sorokiniana and $N$. oculata were higher at $25^{\circ} \mathrm{C}$, while $D$. tertiolecta and $D$. primolecta demonstrated a higher SGR observed at $30^{\circ} \mathrm{C}$. Student's $t$-test, on the other hand, revealed no significant differences $(p>0.05)$ between the microalgae growth at both incubation temperatures. The optimum temperature for various microalgae and macroalgae was found to be between $20^{\circ} \mathrm{C}$ and $30^{\circ} \mathrm{C}$ [33]. Chlorella minutissima grows best at temperatures between $10^{\circ} \mathrm{C}$ and $30^{\circ} \mathrm{C}$; however, at temperatures beyond $35^{\circ} \mathrm{C}$, the particular growth rate decreases [34]. The Chlorella strain's growth was impeded at temperatures above $30^{\circ} \mathrm{C}$, and the rate of growth was lowered by $17 \%$ at $35^{\circ} \mathrm{C}$ compared to $30^{\circ} \mathrm{C}$. An increase in temperature, according to Converti et al. [35], would have resulted in an abrupt disruption of Chlorella vulgaris's further development and consequent cell death. Another study found that $30^{\circ} \mathrm{C}$ was the best temperature for Chlorella pyrenoidosa growth [36]. Chlorella 

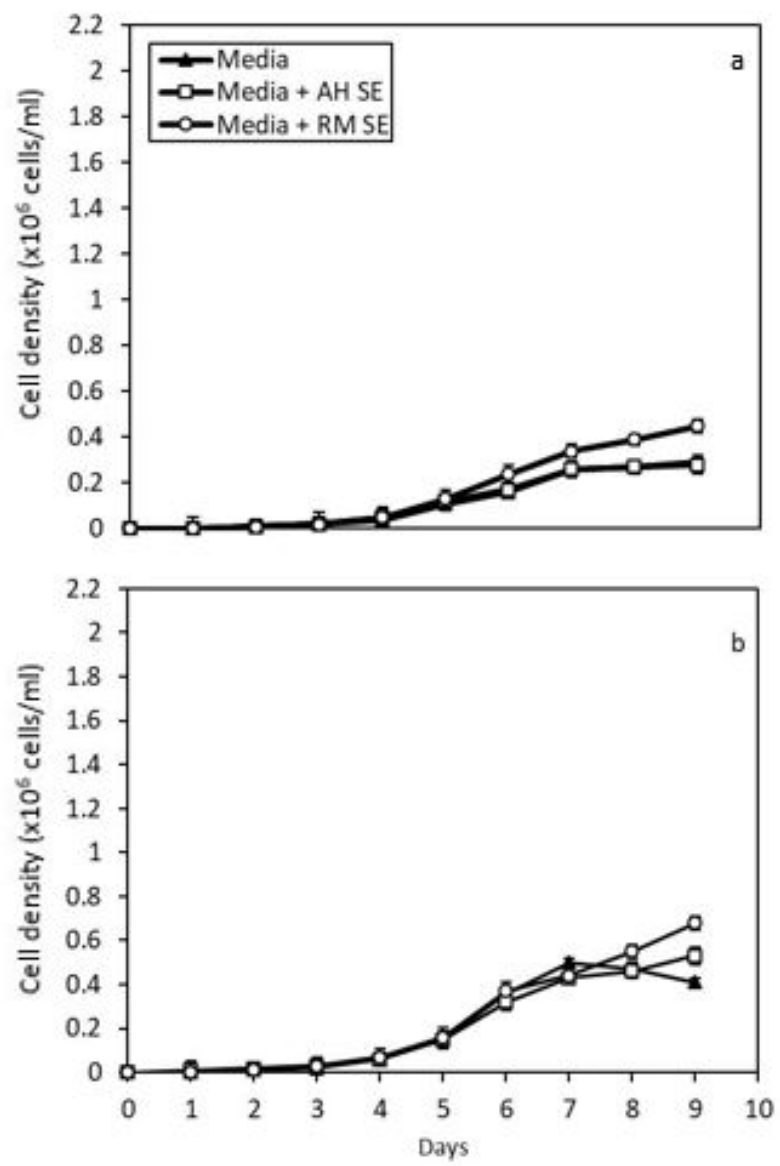

Figure 4: OD at $680 \mathrm{~nm}$ of the D. tertiolecta in media, media + AH SE, and media $+\mathrm{RM} \mathrm{SE}$ at $25^{\circ} \mathrm{C} \mathrm{(a)} \mathrm{and} 30^{\circ} \mathrm{C}$ (b). Error bars represent standard deviation $(n=6)$. Mean values are significantly different $(p<0.05)$ using ANOVA.

sp. isolated from severe habitats could grow at temperatures as high as $44^{\circ} \mathrm{C}-51^{\circ} \mathrm{C}$ [37]. As a result, different microalgae species have varied optimum growth temperatures, and their starting habitat also affects microalgal growth at specific temperatures.

The $\mathrm{AH}$ is the most valuable piece of lowland dipterocarp forest remains covering 1,248 ha currently managed by Universiti Putra Malaysia (UPM). According to Neto et al. [38], soil taken from the $\mathrm{AH}$ at various depths and based on the measurement of trees above ground demonstrates a high percentage of carbon content. Likewise, the RM is a significant block of a remaining peat forest in Peninsular Malaysia and plays an important role in carbon storage, to prevent global warming and to maintain biodiversity conservation [39]. It is also called a peat swamp forest as it forms carbon-rich soil by aggregating partially decomposed organic matter under waterlogged conditions. The carbon in the soil could support algal growth and other essential elements such as nitrogen and phosphorus [8].

Modified media, which contain SEs, may show outstanding results compared to artificial ones. SEs are thought to have a significant impact in the augmentation of microalgae growth due to their composition [2]. In the present study, the growth of microalgae on the two SEs showed no significant differences among different microalgae compared to the control. The SGR in media + RM SE showed a significantly
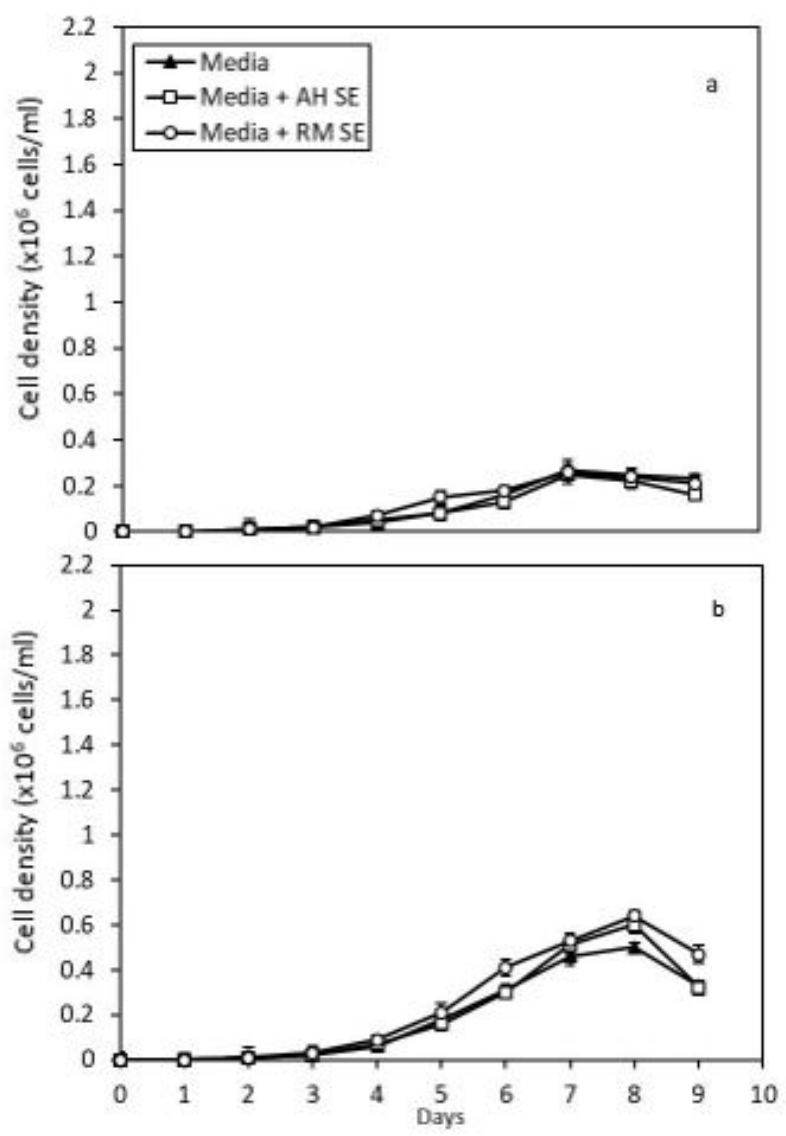

Figure 5: OD at $680 \mathrm{~nm}$ of the $D$. primolecta in media, media $+\mathrm{AH} \mathrm{SE}$, and media $+\mathrm{RM} \mathrm{SE}$ at $25^{\circ} \mathrm{C}$ (a) and $30^{\circ} \mathrm{C}(\mathrm{b})$. Error bars represent standard deviation $(n=6)$. Mean values are significantly different $(p<0.05)$ using ANOVA.

higher growth rate for all species at $25^{\circ} \mathrm{C}$. In addition, media $+\mathrm{AH} \mathrm{SE}$ did not show significant differences for microalgae in comparison to the control. These findings suggested that higher soil organic matter in RM SE enhances the growth of microalgae. To prove this, [5] noted that Nannochloropsis sp. grows well in a modified Walne and F/2 medium containing $3.5 \%$ and $7.0 \%$ SE concentration, respectively. The addition of SEs as organic nutrients or mineral salts to the wellknown artificial media can increase microalgae biomass.

Microalgal mass-culture systems were developed for their massive usage in human nutrition, aquaculture feeds, biofertilizers, cosmetics, food colorants, and biofuels [40,41]. Based on the taxonomy and physiology of microalgae, there is a growing demand for sophisticated microalgae products [40]. Recently, microalgal product companies have come up with novel innovations for the manufacturing of biomass and have downstreamed this biomass into highly differentiated products [40]. Along with that, a modified culture medium with SE could assist the mass culture of microalgae. Mass-culturing microalgae in an artificial culture medium would be expensive, which could be compensated using $\mathrm{SE}$ to provide low-cost, high biomass production. The natural growth promoters in soils could increase the microalgae growth rate compared to other artificial media. 


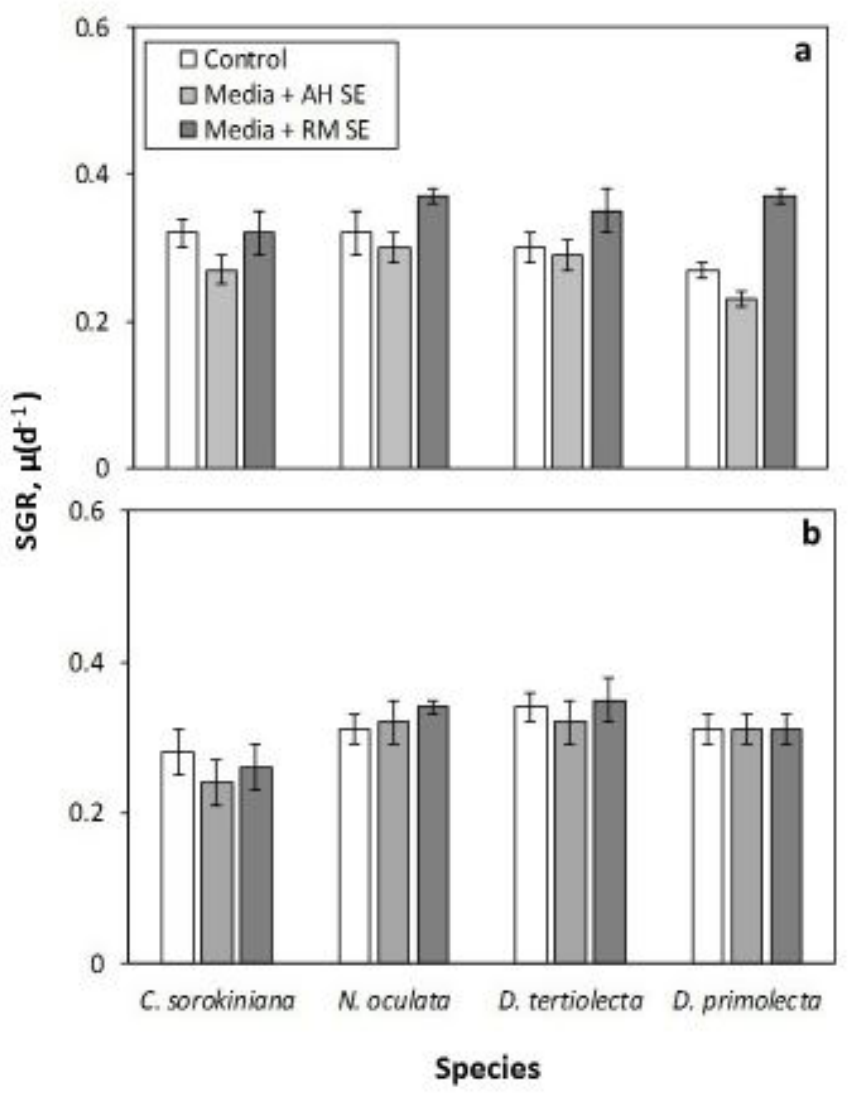

Figure 6: SGR, $\mu$ of C. sorokiniana, $N$. oculata, D. tertiolecta, and $D$. primolecta on media, media $+\mathrm{AH} \mathrm{SE}$, and media $+\mathrm{RM} \mathrm{SE}$ at $25^{\circ} \mathrm{C}$ (a) and $30^{\circ} \mathrm{C}(\mathrm{b})$. Error bars represent standard deviation $(n=6)$. Mean values are significantly different $(p<0.05)$ using ANOVA.

\section{CONCLUSION}

The SEs of AH and RM were utilized as natural growth promoters, which increased the growth of $C$. sorokiniana, $N$. oculata, D. tertiolecta, and $D$. primolecta compared to control without SE. At the incubation temperature of $25^{\circ} \mathrm{C}$, media $+\mathrm{RM}$ SE showed higher SGR than the control for all microalgae. Apart from that, control and media + AH SE did not show any significant differences in microalgal growth. The RM SE, composed of higher soil organic matters, influences microalgae growth at both incubation temperatures. However, the overall growth of $C$. sorokiniana and $N$. oculata was reduced at $30^{\circ} \mathrm{C}$ compared to $25^{\circ} \mathrm{C}$, indicating that $25^{\circ} \mathrm{C}$ is the optimum temperature for these two algal species. In contrast, $D$. tertiolecta and D. primolecta have an optimum temperature at $30^{\circ} \mathrm{C}$. It can be concluded that media + RM SE has the best natural growthenhancing nutrient for microalgae, and different microalgae grew well at different optimum temperatures. As a result, the findings of this study will enhance the microalgae production industry by lowering the cost of mass crop enrichment with SEs while also potentially increasing microalgae growth and nutritional value.

\section{AUTHORS' CONTRIBUTIONS}

MFA and EFH conceptualized the study. WMIWMZ designed the methodology. FS used the software. NSY and MFA validated the data. KK conducted the formal analysis. VSK conducted the investigation. WMIWMZ collected the resources. KA curated the data. NSY wrote and prepared the original draft. NK wrote, reviewed, and edited the paper. HA visualized the study. VSK supervised. KK conducted project administration. MNM acquired the funding. All authors read and approved the published version of the manuscript.

\section{ACKNOWLEDGMENTS}

Special thanks are due to the Ministry of Higher Education Malaysia (MOHE) and Japan Science and Technology Agency (JST)/Japan International Cooperation Agency (JICA) for the funding through the project of JPMJSA1509 and the SATREPSCOSMOS Matching Fund.

\section{CONFLICTS OF INTEREST}

The authors report no financial or any other conflicts of interest in this work.

\section{ETHICAL APPROVALS}

This study does not involve experiments on animals or human subjects.

\section{PUBLISHER'S NOTE}

This journal remains neutral with regard to jurisdictional claims in published institutional affiliation.

\section{REFERENCES}

1. Needelman BA. What are soils. In: Nature education knowledge, United States, 2013.

2. Idris A, Atta M, Bukhari A. Effect of soil extracts concentration on specific growth rate and lipid content of Chlorella vulgaris in bolds basal medium. Mal J Fund Appl Sci 2014;10(2):96-100.

3. Prakash AA, Rashid MA. Influence of humic substances on the growth of marine phytoplankton: dinoflagellates 1 . Limnol Oceanogr 1968;13(4):598-606.

4. Costa JAV, de Morais MG. An open pond system for microalgal cultivation. In: Biofuels from algae, Elsevier, London, pp 1-22, 2014

5. Teo CL, Idris A, Akhtar J. Effect of soil extract in different culture medium for marine microalgae's biomass and lipid production in biodiesel production. J Life Sci Technol 2016;4(1):22-5.

6. Bot A, Benites J. Organic matter decomposition and the soil food web. The importance of soil organic matter: key to drought-resistant soil and sustained food production (No. 80). Food and Agriculture Organization of the United Nation, Rome, Italy, 2005

7. Hammoud N, Mayhoub H, Allaan T. The influence of illumination and soil extract concentration on growth rate and protein content of Cosmarium subtumidum microalgae. J Entomol Zool Stud 2015;3(5):27-31.

8. Harrison PJ, Berges JA. Marine culture media. In: Andersen RA (ed.). Algal culturing techniques, Elsevier Academic Press, Burlington, pp 21-34, 2005.

9. Ramaraj R, Tsai DD, Chen PH. Algae growth in natural water resources. J Soil Water Conserv 2010;42(4):439-50.

10. Guzmán-Murillo MA, López-Bolaños CC, Ledesma-Verdejo $\mathrm{T}$, Roldan-Libenson G, Cadena-Roa MA, Ascencio F. Effects of fertilizerbased culture media on the production of exocellular polysaccharides and cellular superoxide dismutase by Phaeodactylum tricornutum (Bohlin). J Appl Phycol 2007;19(1):33-41. 
11. Ashraf M, Javaid M, Rashid T, Ayub M, Zafar A, Ali S, et al. Replacement of expensive pure nutritive media with low cost commercial fertilizers for mass culture of freshwater algae. Chlorella vulgaris. Int J Agri Biol 2011;13(4):484-90.

12. Okauchi M. The studies on phytoplankton production in Japan. In: Rotifers and micro-algae system, (ed) Fulks, W \& Main, K.L, Proceeding of U.S Asia Workshop, Honolulu, HI, 1991.

13. Muhamad IS, Seca G, Osumanu HA, Nik M. Comparison of selected chemical properties of peat swamp soil before and after timber harvesting. Am J Environ Sci 2010;6(2):164-7.

14. Adon R, Bakar I, Wijeyesekera DC, Zainorabidin A. Overview of the sustainable uses of peat soil in Malaysia with some relevant geotechnical assessments. Int J Integr Eng 2012;4(4):38-46.

15. Radin Mohamed RMS, Chan CM, Senin H, Mohd Kassim AH. Feasibility of the direct filtration over peat filter media for bathroom greywater treatment. J Mater Environ Sci 2014;5(6):2021-9.

16. Cruz YR, Aranda DA, Seidl PR, Diaz GC, Carliz RG, Fortes MM, et al. Cultivation systems of microalgae for the production of biofuels. In: Biernat K (ed.). Biofuels: state of development, IntechOpen, pp 199-218, 2018.

17. Watanabe MM. Freshwater culture media. In: Andersen RA (ed.). Algal culturing techniques, Elsevier Academic Press, London, pp 13-20, 2005.

18. Khatoon H, Banerjee S, Syakir Syahiran M, Mat Noordin NB, Munafi Ambok Bolong A, Endut A. Re-use of aquaculture wastewater in cultivating microalgae as live feed for aquaculture organisms. Desalin Water Treat 2016;57(60):29295-302.

19. Tillich UM, Wolter N, Franke P, Dühring U, Frohme M. Screening and genetic characterization of thermo-tolerant Synechocystis sp. PCC6803 strains created by adaptive evolution. BMC Biotechnol 2014;14(1):66.

20. Katayama T, Kishi M, Takahashi K, Furuya K, Abd Wahid ME, Khatoon $\mathrm{H}$, et al. Isolation of lipid-rich marine microalgae by flow cytometric screening with Nile Red staining. Aquacu Int 2019;27(2):509-18.

21. Arumugam K, Ahmad MF, Yaacob NS, Ikram WM, Maniyam MN, Abdullah $\mathrm{H}$, et al. Enhancement of targeted microalgae species growth using aquaculture sludge extracts. Heliyon 2020;6(7):e04556.

22. Lürling M, Eshetu F, Faassen EJ, Kosten S, Huszar VL. Comparison of cyanobacterial and green algal growth rates at different temperatures. Freshwater Biol 2013;58(3):552-9.

23. Dziosa K, Makowska M. Monitoring of Chlorella sp. growth based on the optical density measurement. Institute for Sustainable Technologies - National Research Institute, Radom, pp 197-206, 2016.

24. Jabłońska E, Falkowski T, Chormański J, Jarzombkowski F, Kłosowski $\mathrm{S}$, Okruszko T, et al. Understanding the long term ecosystem stability of a fen mire by analyzing subsurface geology, eco-hydrology and nutrient stoichiometry-case study of the Rospuda Valley (NE Poland). Wetlands 2014;34(4):815-28.

25. Yu Q, Elser JJ, He N, Wu H, Chen Q, Zhang G, et al. Stoichiometric homeostasis of vascular plants in the Inner Mongolia grassland. Oecologia 2011;166(1):1-10.

26. Zhang Z, Xue Z, Lyu X, Tong S, Jiang M. Scaling of soil carbon, nitrogen, phosphorus and $\mathrm{C}: \mathrm{N}$ : $\mathrm{P}$ ratio patterns in peatlands of China. Chin Geogr Sci 2017;27(4):507-15.
27. Geider R, La Roche J. Redfield revisited: variability of C: N: P in marine microalgae and its biochemical basis. Eur J Phycol 2002;37(1):1-17.

28. Cleveland CC, Liptzin D. C: N: P stoichiometry in soil: is there a "Redfield ratio" for the microbial biomass? Biogeochemistry 2007;85(3):235-52.

29. Raven JA, Geider RJ. Temperature and algal growth. New Phytol 1988;110(4):441-61.

30. Ras M, Steyer JP, Bernard O. Temperature effect on microalgae: a crucial factor for outdoor production. Rev Environ Sci Bio/Technol 2013;12(2):153-64.

31. Van Wagenen J, Holdt SL, De Francisci D, Valverde-Pérez B, Plósz BG, Angelidaki I. Microplate-based method for high-throughput screening of microalgae growth potential. Bioresour Technol 2014;169:566-72.

32. Sharma AK, Sahoo PK, Singhal S, Patel A. Impact of various media and organic carbon sources on biofuel production potential from Chlorella spp. 3. Biotech 2016;6(2):116.

33. Singh SP, Singh P. Effect of temperature and light on the growth of algae species: a review. Renew Sustain Energy Rev 2015;50:431-44.

34. Aleya L, Dauta A, Reynolds CS. Endogenous regulation of the growth-rate responses of a spring-dwelling strain of the freshwater alga, Chlorella minutissima, to light and temperature. Eur J Protistol 2011;47(4):239-44.

35. Converti A, Casazza AA, Ortiz EY, Perego P, Del Borghi M. Effect of temperature and nitrogen concentration on the growth and lipid content of Nannochloropsis oculata and Chlorella vulgaris for biodiesel production. Chem Eng Process: Process Intensif 2007;48(6):1146-51.

36. Han F, Wang W, Li Y, Shen G, Wan M, Wang J. Changes of biomass, lipid content and fatty acids composition under a light-dark cyclic culture of Chlorella pyrenoidosa in response to different temperature. Bioresour Technol 2013;132:182-9.

37. Gacheva G, Pilarski, P. The resistance of a new strain Chlorella sp. R-06/2, isolated from an extreme habitat to environmental stress factors. Gen Appl Plant Physiol 2008;34:347-60.

38. Neto V, Ainuddin NA, Wong MY, Ting HL. Contributions of forest biomass and organic matter to above-and belowground carbon contents at Ayer Hitam Forest Reserve, Malaysia. J Trop For Sci 2012;217-30.

39. Lo J, Quoi LP, Visal S. Some preliminary observations on peat-forming mangroves in Botum Sakor, Cambodia. Mires Peat 2018;22:1-10

40. Pulz O, Gross W. Valuable products from biotechnology of microalgae. Appl Microbiol Biotechnol 2004;65(6):635-48.

41. Priyadarshani I, Rath B. Commercial and industrial applications of micro algae-a review. J Algal Biomass Util 2012;3(4):89-100.

How to cite this article:

Arumugam K, Yaacob NS, Abdullah H, Ahmad MF, Maniyam

MN, Hashim EF, Sjahrir F, Ikram WM, Komatsu K, Kuwahara

VS. Growth-promoting effects of marine microalgae species using tropical forest soil extracts. J Appl Biol Biotech 2022; 10(02):125-132. 